Marzęda Magdalena, Blicharz Agnieszka, Drozd Małgorzata, Piecewicz-Szczęsna Halina. Juvenile angiofibroma: etiology, diagnosis, treatment. Journal of Education, Health and Sport. 2020;10(9):263-269. eISSN 2391-8306. DOI http://dx.doi.org/10.12775/JEHS.2020.10.09.029

https://apcz.umk.pl/czasopisma/index.php/JEHS/article/view/JEHS.2020.10.09.029

https://zenodo.org/record/4024473

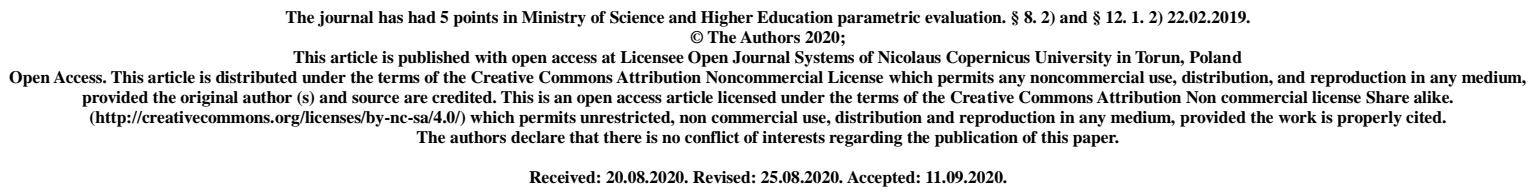

\title{
Juvenile angiofibroma: etiology, diagnosis, treatment
}

\section{Magdalena Marzęda ${ }^{1}$, Agnieszka Blicharz ${ }^{1}$, Małgorzata Drozd ${ }^{1}$, Halina Piecewicz-Szczęsna ${ }^{2}$}

\footnotetext{
${ }^{1}$ Student Research Circle at the Department of Epidemiology and Clinical Research Methodology, Medical University of Lublin

${ }^{2}$ Department of Epidemiology and Clinical Research Methodology, Medical University of Lublin
}

Corresponding author: Halina Piecewicz-Szczęsna, e-mail: halpiec@wp.pl

ORCID ID:

Magdalena Marzęda https://orcid.org/0000-0003-4397-5214; mmarzeda@ gmail.com Agnieszka Blicharz https://orcid.org/0000-0003-4536-0651;

agnieszkablicharz9603@gmail.com

Małgorzata Drozd https://orcid.org/0000-0002-0710-2451; drozd.malg@ gmail.com Halina Piecewicz-Szczęsna https://orcid.org/0000-0002-0573-7226; halpiec@wp.pl 


\begin{abstract}
:
Introduction and purpose: Juvenile angiofibroma is a rare neoplasm of the nasopharynx. It occurs almost exclusively in boys during adolescence. It is a richly vascularized neoplasm which, despite its benign histopathological character, tends to invasive growth and recurrence. The aim of the study is to review current data on juvenile angiofibroma.

Brief description of the state of knowledge: Juvenile angiofibroma primary develops on the posterolateral wall of the nasal cavity, growing out of the wedge-palatal opening. Common symptoms resulting from its location, there are bleeding and nasal obstruction. Tumor diagnosis is based in imaging tests - CT and MRI, in which juvenile angiofibroma exhibits some distinctive features. CT and MR examinations demonstrate the typical the location and route of spread of juvenile angiofibroma and allow to assess the extent of the tumor. The angiography allows for confirmation diagnosis of a vascular tumor and enables preoperative embolization. Surgical treatment is the most common therapeutic procedure and irradiating the tumor, depending on its location. Due to the vascularnature of the tumor, the basic preoperative procedure is tumor vessel embolization, which allows reducing blood loss during surgery.
\end{abstract}

Conclusions: Juvenile angiofibroma shows some characteristic features - it occurs at a similar age, in one sex and in one localization in the organism. Due to the invasive tumor growth, the risk of bone destruction and relapse, the role of imaging tests is important, allowing the diagnosis of a tumor at an early stage of its development.

Key words: computed tomography; digital subtraction angiography; embolization; juvenile nasopharyngeal angiofibroma; magnetic resonance imaging

\title{
Introduction and purpose
}

Juvenile angiofibroma is a rare tumor of the nasopharynx. It accounts for $0.05 \%$ of all head and neck cancers. At the same time, it is the most common benign neoplasm occurring in the nasopharynx and nasal cavity [1]. It occurs with a frequency of 1: 4,000 to 1: 15,000 cases [2]. The incidence is greater in India and the Middle East than in Europe [3]. Juvenile angiofibroma affects almost exclusively adolescent boys. In the clinical picture of juvenile angiofibroma, there is a characteristic triad of symptoms: nasal obstruction (80\%), recurrent nosebleeds $(60 \%)$ and the mass of the tumor visible in the nasopharynx [1]. In advanced tumors, there may also be swelling and distortion of the cheek, exophthalmos, double vision, headache (usually secondary to obstruction of the paranasal sinuses), or hearing loss [4]. Symptoms typically occur six months to a year prior to diagnosis [5]. Despite its mild histopathological character, juvenile angiofibroma has a tendency to invasive growth, bone destruction and recurrence [6]. This tumor is very vascularized. Therefore, tumor biopsy is at risk of severe bleeding, and diagnosis is based on clinical symptoms and imaging tests.

The aim of the study is to review the current data on the etiology and epidemiology, as well as the diagnosis and treatment options for patients with juvenile angiofibroma. 


\section{Description of the state of knowledge}

\section{Etiology}

The exact cause of juvenile angiofibroma is unknown. It is speculated that genetic and hormonal factors have the greatest influence on the incidence of cancer, as the tumor occurs almost exclusively in boys aged 9-19. In rare cases, the angiofibroma may appear in older men or women, but in such situations the neoplasm should be more closely examined pathologically (pathomorphologically) and genetically [1].

Studies on the influence of hormones on the growth and development of juvenile angiofibroma do not provide clear answers. The presence of estrogen, progesterone and androgen receptors within the tumor has been noted [7]. Additionally, the tests showed tumor growth even many years after the end of treatment due to the administration of exogenous testosterone [8]. On the other hand, other analyzes revealed the absence of estrogen and progesterone receptors in any component of the tumor, and nuclear androgen receptors with variable immunoreactivity were found in a minority of tumor endothelial cells and stroma [9]. Therefore, the role of testosterone in the formation and development of juvenile angiofibroma remains unclear.

Genetic studies are difficult to interpret from an epidemiological point of view due to the rarity of cancer. Genetic changes in the angiofibroma were detected in the endothelium and the stroma of the tumor [10]. These are mainly deletions within chromosome 17 that affect the TP53 and HER-2 suppressor gene (human epidermal growth factor receptor) [11]. The cause of the intensive vascular growth of the tumor may be the excessive expression of the vascular endothelial growth factor receptor, i.e. VEGFR-2 [12]. Additionally, tenascin-C is overexpressed in the tumor stroma. This glycoprotein is often overproduced in the body during an ongoing neoplastic process and contributes to pathological angiogenesis, proliferation, and cell migration [13].

In recent years, theories have appeared suggesting a relationship between the human papillomavirus and juvenile angiofibroma. In the conducted studies it was noticed that HPV can increase the rate of tumor cell proliferation and even be an etiological factor of JNA [14]. There is a vascular theory that explains the period, location and structure of the tumor. It is likely that the artery of the first pharyngeal arch was not completely regressed during embryonic development. Its remnant is located near the spheno-palatal opening, i.e. the place from which the tumor typically begins to grow. During puberty, it may be sensitive to growth stimulation and grow uncontrollably in the form of a richly vascularized tumor [11].

\section{Diagnostics}

The diagnosis of juvenile angiofibroma is based on a medical history, clinical examination with nasal endoscopy, and imaging diagnostics. On a rhinoscopic examination, early angiofibromas appear as rounded or lobular, reddish masses, sessile or pedunculated. There may be ulcerations or purulent exudate on their surface [10]. Often, the symptoms of angiofibroma are confused at an early stage with rhinitis, sinusitis, or a choanal polyp, which delays the correct diagnosis [15]. Primarily, the tumor grows on the posterolateral wall of the nasal cavity. The tumor grows out of the wedge-palatal opening and from there it spreads initially in the direction of the least resistance - to the nasopharynx. This is the early stage of the tumor. 
In the further course of the disease, lateral spread to the pterygo-palatine fossa and up to the sphenoid sinus with destruction of its lower wall is revealed [16]. This is an advanced stage of cancer. Intracranial invasion of angiofibroma occurs in the advanced stage of the disease and may occur in several ways $[16,17]$ :

- from the pterygoid palatine fossa and the subtemporal fossa to the medial fossa of the skull,

- from the sphenoid sinus through direct erosion of its upper wall into the area of the pituitary gland and / or into the cavernous sinus,

- from the ethmoid sinus to the anterior cranial fossa.

Juvenile angiofibroma has characteristic clinical symptoms: recurrent bleeding and increasing nasal obstruction. Bleeding and stuffy nose are a consequence of the location of the tumor in the nasopharynx. Depending on the size and directions of tumor expansion, other symptoms may appear. The tumor grows into the nasal cavity, closes the mouth of the maxillary sinus and destroys its wall. This can cause mucus build-up and inflammation in the maxillary sinus. The enlarging tumor in the nasopharynx also closes the orifice of the Eustachian tube and may lead to the accumulation of fluid in the mastoid cells and even to otitis media and hearing loss. The angiofibroma, spreading laterally from the pterygo-palatine fossa to the sub-temporal fossa, and then into the orbital fissure and orbit, may push the eyeball out, causing exophthalmia and visual disturbances. In advanced forms, the tumor may penetrate the cranial cavity, locating next to the sella turcica, giving symptoms of increased intracranial pressure and other neurological symptoms [1,18]. Cheek deformity caused by a significant lateral tumor growth is a rare situation. Imaging tests in the diagnosis of juvenile angiofibroma are of great importance for proper diagnosis. A tumor biopsy is not recommended as it carries the risk of heavy bleeding. Thanks to modern imaging techniques, it is possible to recognize a tumor in the early stages of its development. Nevertheless, as many as $40 \%$ of cases are diagnosed in the advanced stage of the disease, and in about $17 \%$ of patients the tumor grows intracranially [15]. Both CT (computed tomography) and MRI (magnetic resonance imaging) show characteristic features of angiofibroma helpful in the differential diagnosis. CT is a good picture of bone changes in the course of the disease. The earliest visible bone change is the destruction of the base of the pterygoid process of the sphenoid bone by a tumor growing in the area of the pterygo-palatine foramen [17]. In addition, a typical symptom of CT scan and lateral skull scan is the Holman-Miller symptom, i.e. an anterior displacement of the posterior wall of the maxillary sinus [2,17]. It is accompanied by the widening of the pterygo-palatal fossa. Tumor expansion may cause erosion of the posterior wall of the maxillary sinus, destruction of the sphenoid sinus wall, or widening of orbital fissures [19, 20]. The advantage of magnetic resonance imaging is good differentiation of soft tissues, thanks to which it is possible to accurately determine the tumor boundaries. It is a key method in assessing intracranial angiofibroma hyperplasia, the tumor-to-dura mater ratio, and vital structures such as the cavernous sinus, internal carotid artery, and pituitary gland. A very important aspect is the penetration of the tumor into the spongy part of the sphenoid bone in the area of the wedge-palatal opening and the base of the pterygoid process. Tumor invasion in this area increases the risk of recurrence and requires thorough surgical debridement.

Magnetic resonance images with the suppression of the adipose tissue signal and the use of a contrast agent are very useful in the detection and precise determination of the limits of such 
invasion. MRI can also distinguish the tumor from residual secretions or swelling of the mucosa in the paranasal sinuses. This method is also most sensitive in detecting residual or recurrent tumor [17,20]. Angiography (DSA - Digital Subtraction Angiography) is the final test in a diagnostic algorithm, usually performed as a pre-operative embolization. The examination shows a very rich vascularization characteristic of the angiofibroma and is the final confirmation of the diagnosis, determined on the basis of non-invasive imaging methods. It also allows to identify the main vessel supplying the tumor - most often it is the maxillary artery, a branch of the external carotid artery [16]. Depending on the extent of the tumor and the occupancy of subsequent anatomical spaces, the ascending pharyngeal and facial arteries may also be involved in vascularization, and if the tumor crosses the midline, also the opposite maxillary artery. In the case of intracranial invasion, an additional source of vascularization may be the internal carotid artery [5]. Preoperative embolization is considered to be an important element of therapeutic management. It reduces the intraoperative blood loss by 70\%, which improves the assessment of the surgical field and reduces the need for intraoperative blood transfusions [15]. When the tumor is supplied through both external carotid arteries, the procedure is performed on both sides [15]. It is recommended to perform embolization 24-48 hours before the planned surgery [21]. The most commonly used materials for this are: polyvinyl alcohol (PVA), microparticles, cyanoacrylate adhesives, as well as ethylene-vinyl alcohol Onyx [22].

\section{Treatment}

The methods used in the therapeutic management of patients with juvenile angiofibroma include surgery and radiation. Attempts to treat the angiofibroma with hormones or chemotherapy did not bring the expected results [23]. There have also been some reports of spontaneous tumor regression without treatment [24]. Surgical removal is the basic and widely recognized method of treatment of angiofibromas. Imaging tests are crucial for assessing the extent of the tumor and, consequently, selecting the appropriate treatment method. The surgical operation is to remove the tumor completely "en block". Due to the invasive nature of tumor growth, penetrating into the natural crevices and openings of the skull base, complete resection in this complicated anatomical region with restricted access is very difficult. Visualization of all tumor branches allows for the adjustment of the optimal surgical approach, the choice of which depends mainly on the extent of the tumor and the operator's experience. Nowadays, the development of endoscopic techniques has made it possible to introduce this minimally invasive surgical method into juvenile angiofibroma surgery and many authors prefer this technique over open accesses [24]. For intracranial tumors, surgery or radiation therapy is considered. Radiotherapy is used in patients with advanced intracranial tumors as the primary treatment, as well as in patients after the first, surgical stage of treatment, leaving tumor remnants in the area of vital intracranial structures, or when the disease has recurred in this area. In some cases, in patients with difficult to remove intracranial tumor remnants, follow-up is used in subsequent follow-up examinations, with reoperation postponed until there is clear evidence of residual tumor progression.

Despite the benign nature of the angiofibroma, relapses, usually caused by incomplete resection of the tumor, are frequent and range from 18 to $45 \%$ depending on the stage [16]. They most often appear between 6 and 36 months after the operation, the minimum follow-up 
is 3 years, and in most cases it lasts 5 years [16]. The risk of recurrence is related to the involvement of individual anatomical regions, the greatest risk is related to intracranial invasion. Imaging studies are crucial in assessing the radicality of the procedure and visualizing tumor remnants, as it may regrow asymptomatically, in an area not available clinically, or spread submucosa. Thanks to the early detection of relapse, surgical intervention is limited and the treatment outcomes are better. Some authors report that the residual disease may not increase and may even undergo involution [13]. In a patient after radical surgery, the first examination to show new anatomical relations should be performed after about 6 months, when the majority of immediate postoperative changes (edema, granulation tissue) have subsided and the development of a large recurrence is unlikely. Subsequent check-ups are usually performed every 6-12 months. The healing process is supported by a constant or decreasing field of contrast enhancement, while its enlargement, new bulging and / or swelling within the soft tissues, as well as new signs of bone destruction suggest tumor regrowth. In patients after incomplete resection of an angiofibroma with an intracranial protrusion, an MRI examination is recommended 2 months after the surgery, and then twice a year throughout puberty $[16,25]$.

\section{Summary and conclusions}

Juvenile angiofibroma is a rare neoplasm of the nasopharynx and, at the same time, the most common benign neoplasm of the head and neck area. The triad of symptoms is characteristic: nasal obstruction, nosebleeds and the mass of the tumor visible in the nasopharynx. The appearance of such symptoms in adolescent boys is an indication for further tests. CT and MR examinations demonstrate the typical location and pathways of the tumor, and also allow the assessment of its extent. Numerous abnormal tumor vessels visible in angiography confirm its vascular nature. Angiography also enables preoperative embolization. Imaging tests play an important role in making the diagnosis. They allow to avoid performing a biopsy, which is at risk of heavy bleeding. Early diagnosis avoids the destruction of the surrounding tissues in an advanced stage of cancer, which contributes to better treatment outcomes. Despite surgical treatment, strong vascularity and a tendency to local recurrence mean that patients with juvenile angiofibroma require multiple surgical treatment.

\section{List of references}

1. Lopez F, Triantafyllou A, Snyderman C, et al. Nasal juvenile angiofibroma: Current perspectives with emphasis on management. Head \& Neck. 2017;39(5):1033-1045.

2. Łukomski M., Danilewicz M., Pajor A. Naczyniakowłókniak młodzieńczy u dorosłych. [Juvenile angiofibroma in adults]. Otolaryngologia Polska. [Polish otolaryngology]. 2008;LXII(1):20-26. Polish.

3. Lund VJ, Stammberger H, Fokkens WJ, et al. European position paper on the anatomical terminology of the internal nose and paranasal sinuses. Rhinol Suppl. 2014; 24: 1- 34.

4. Pucher B., Jończyk-Potoczna K., Grzegorowski M., Ryglewicz M., Szydłowski J. Ocena wyników leczenia chirurgicznego chorych z naczyniakowłókniakiem młodzieńczym. [Assessent of the surgical treatment in patients with juvenile angiofibroma]. Otolaryngologia. [Otolaryngology]. 2015;14(1):15-19. Polish.

5. Szymańska A., Jargiełło T., Drelich-Zbroja A., Szymański M., Szczerbo-Trojanowska M. Naczyniakowłókniak młodzieńczy: znaczenie diagnostyki angiograficznej i przedoperacyjnej embolizacji w postępowaniu leczniczym. [Juvenile angiofibroma: the role of diagnostic angiography and preoperative embolization in treatment]. Postępy Nauk Medycznych. [Advances in Medical Sciences]. 2012;XXV(5):459-463. Polish. 
6. Sawicki P., Kaźmierczak H. Trudności lecznicze w naczyniakowłókniaku młodzieńczym. [The difficulties in treating juvenile angiofibroma]. Acta Angiol. 2010;16(4):181-189. Polish.

7. Liu Z, Wang J, Wang $\mathrm{H}$, et al. Hormonal receptors and vascular endothelial growth factor in juvenile nasopharyngeal angiofibroma: immunohistochemical and tissue microarray analysis. Acta Otolaryngol 2015;135:51-57.

8. Riggs S, Orlandi RR. Juvenile nasopharyngeal angiofibroma recurrence associated with exogenous testosterone therapy. Head Neck 2010;32:812-815.

9. Gatalica Z. Immunohistochemical analysis of steroid hormone receptors in nasopharyngeal angiofibromas. Cancer Lett 1998;127:89-93.

10. Silveira SM, Custódio Domingues MA, Butugan O, Brentani MM, Rogatto SR. Tumor microenvironmental genomic alterations in juvenile nasopharyngeal angiofibroma. Head Neck 2012;34:485-492.

11. Schick B, Veldung B, Wemmert S, et al. p53 and Her-2/neu in juvenile angiofibromas. Oncol Rep 2005;13:453-457.

12. Ponti G, Losi L, Pellacani G, et al. Wnt pathway, angiogenetic and hormonal markers in sporadic and familial adenomatous polyposis-associated juvenile nasopharyngeal angiofibromas (JNA). Appl Immunohistochem Mol Morphol 2008;16:173-178.

13. Renkonen S, Heikkilä P, Haglund C, Mäkitie AA, Hagström J. Tenascin-C, GLUT-1, and syndecan-2 expression in juvenile nasopharyngeal angiofibroma: correlations to vessel density and tumor stage. Head Neck 2013;35:1036-1042.

14. Mishra A, Sachadeva M, Jain A, Shukla NM, Pandey A. Human papilloma virus in juvenile nasopharyngeal angiofibroma: possible recent trend. Am J Otolaryngol 2016;37:317-322.

15. Leong SC. A systematic review of surgical outcomes for advanced juvenile nasopharyngeal angiofibroma with intracranial involvement. Laryngoscope 2013; 123: 1125- 1131.

16. Gołąbek W., Szymańska A., Szymański M., Czekajska-Chehab E., Jargiełło T. Juvenile nasopharyngeal angiofibroma with intracranial extension - diagnosis and treatment. Otolaryngologia Polska. 2020;7 (2): 1-7.

17. Szymańska A, Szymański M, Czekajska-Chehab E, Szczerbo-Trojanowska M. Invasive growth patterns of juvenile nasopharyngeal angiofibroma:radiological imaging and clinical implications. Acta Radiologica. 2014;55(6):725-731.

18. Bertazzoni G., Schreiber A., Ferrari M., Nicolai P., Contemporary management of juvenile angiofibroma, Current Opinion in Otolaryngology \& Head and Neck Surgery. 2019;27(1): 47-53.

19. Nicolai P, Schreiber A, Bolzoni Villaret A. Juvenile angiofibroma: evolution of management. Int J Pediatr. 2012; 1-11.

20. Szymańska A, Szymański M, Czekajska-Chehab E, Szczerbo-Trojanowska M. Two types of lateral extension in juvenile nasopharyngeal angiofibroma: diagnostic and therapeutic management. European Archives of OtoRhino-Laryngology. 2015;272:159-166.

21. Lutz J, Holtmannspötter M, Flatz W, et al. Preoperative embolization to improve the surgical management and outcome of juvenile nasopharyngeal angiofibroma (JNA) in a single center: 10-year experience. Clin Neuroradiol. 2016; 26: 405- 413 .

22. Safadi A, Schreiber A, Fliss DM, Nicolai P. Juvenile Angiofibroma: Current Management Strategies. Journal of Neurological Surgery Part B: Skull Base. 2018;79(1): 21-30.

23. Hackman T, Snyderman CH, Carrau R, Vescan A, Kassam A. Juvenile nasopharyngeal angiofibroma: the expanded endonasal approach. Am J Rhinol Allergy 2009; 23: 95- 99.

24. Tosun F, Onerci M, Durmaz A, Ugurel S. Spontaneous involution of nasopharyngeal angiofibroma. J Craniofac Surg.2008; 19: 1686- 1689.

25. Deschler DG, Kaplan MJ, Boles R.: Treatment of large juvenile nasopharyngeal angiofibroma. Otolaryngol Head Neck Surg. 1992, 106, 278-284. 